\title{
The use of head helmets to deliver noninvasive ventilatory support: a comprehensive review of technical aspects and clinical findings
}

\author{
Andrea Coppadoro ${ }^{2}$, Elisabetta Zago ${ }^{1,2}$, Fabio Pavan ${ }^{1,2}$, Giuseppe Foti ${ }^{1,2}$ and Giacomo Bellani $i^{1,2^{*}}$ (1)
}

\begin{abstract}
A helmet, comprising a transparent hood and a soft collar, surrounding the patient's head can be used to deliver noninvasive ventilatory support, both as continuous positive airway pressure and noninvasive positive pressure ventilation (NPPV), the latter providing active support for inspiration. In this review, we summarize the technical aspects relevant to this device, particularly how to prevent $\mathrm{CO}_{2}$ rebreathing and improve patient-ventilator synchrony during NPPV. Clinical studies describe the application of helmets in cardiogenic pulmonary oedema, pneumonia, COVID-19, postextubation and immune suppression. A section is dedicated to paediatric use. In summary, helmet therapy can be used safely and effectively to provide NIV during hypoxemic respiratory failure, improving oxygenation and possibly leading to better patient-centred outcomes than other interfaces.
\end{abstract}

Keywords: Noninvasive ventilation, Helmets, COVID-19, Acute respiratory distress syndrome, Continuous positive airway pressure

\section{Introduction}

Noninvasive ventilatory support (NIV) is frequently used in the treatment of several forms of acute (or acute-onchronic) respiratory failure. During the COVID-19 pandemic, increased attention has been devoted to the use of helmets. Helmets have been in use since the early $2000 \mathrm{~s}$ [1-3], albeit mostly only in a few countries, Italy in particular [4]. Given the increasing use of this interface, we considered it worth summarizing the available knowledge on the topic.

A helmet is constituted by a soft (but nonextensible) transparent hood that fits over the patient's entire head without any contact point and is anchored (in some

*Correspondence: giacomo.bellani1@unimib.it

${ }^{2}$ Department of Medicine and Surgery, University of Milan-Bicocca, Via Cadore 48, Monza, MB, Italy

Full list of author information is available at the end of the article cases by a rigid ring) to a soft and extensible collar that fits gently around the patient's neck. The helmet typically has two (or more) connectors for the gas inlet and outlet; $\mathrm{O}_{2}$-enriched gas can be provided by a Venturi system, a turbine flow generator or a ventilator. As discussed in detail below, the advantages of helmets result from their tolerability (noise representing a possible limitation), cost-effectiveness and excellent sealing capability (minimizing leaks), the latter being obtained easily and involving very gentle contact, resulting in minimal risk of soft tissue injury. This review is divided into two main sections. The first is dedicated to the use of helmets in the delivery of continuous positive airway pressure (H-CPAP), typically powered by a continuous free-flow system and a PEEP valve. During CPAP, the patient is free to inhale or exhale, while the pressure within the helmet remains constant, and there is no interaction with a ventilator and no "active" inspiratory support. The 
second section is dedicated to noninvasive positive pressure ventilation (NPPV), which offers active support for inspiration (typically by pressure support) delivered by a mechanical ventilator. CPAP and NPPV are often lumped together under the broad umbrella of "NIV", but distinguishing between these two forms of support is crucial. Particularly in the context of helmets, CPAP and NPPV offer two completely different approaches and mechanisms of action; for reader convenience, we consider paediatric use separately, but the considerations discussed above still apply.

\section{Methods}

We searched PubMed for records published until April 30, 2021, using the following keywords: "helmet CPAP", "CPAP noninvasive ventilation", "helmet ventilation", "helmet pressure support" and "helmet COVID-19" for a total of 559 screened records.

We included articles published in the English language only. Additional file 1 contains a list of excluded articles because they were not relevant (e.g. motorcycle helmets) or because they were reviews, editorial articles, case reports or series with fewer than ten cases. Eventually, 112 studies were identified and included in this review.

\section{Use of helmets to deliver CPAP}

\section{Technical principles of H-CPAP}

As outlined below, the main advantage of delivering CPAP by helmet instead of by face mask is that it offers better pneumatic performance with free-flow systems and is associated with greater patient tolerance; the greatest drawback is the risk of possible $\mathrm{CO}_{2}$ rebreathing.

The simplest configuration of H-CPAP involves a constant flow of fresh gas (at variable $\mathrm{FiO}_{2}$ ) through the helmet that is dispersed in ambient air through a positive end-expiratory pressure (PEEP) valve connected to the expiratory helmet port (Fig. 1, Additional file 2: Figure e1).

An adequate flow of fresh gas in the helmet [5] is required for two main purposes: keeping the positive
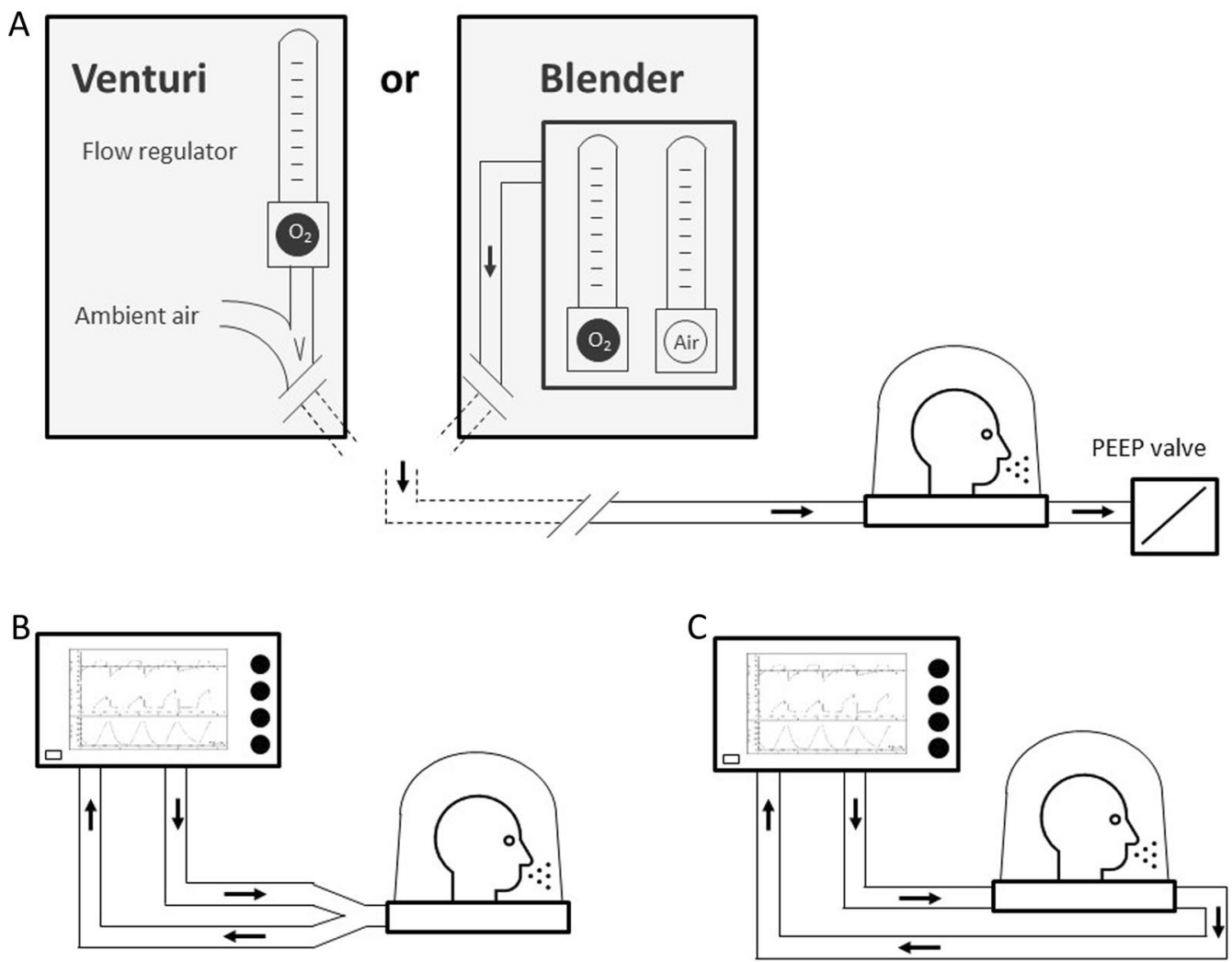

Fig. 1 Schematic drawings of the main helmet circuit configuration possibilities. For free-flow continuous positive airway pressure (CPAP, A), the gas mixture may be generated with either a Venturi system empowered by an oxygen source or an oxygen/air blender. The gas mixture flows through the helmet and is dispersed through a PEEP valve, which maintains a constant positive pressure backwards. An alternative configuration involves the connection of the helmet with a mechanical ventilator to provide noninvasive positive pressure ventilation, typically with the pressure support mode (NPPV) by either a single port (B) connected to the circuit $Y$ piece (condition associated with a higher risk of $\mathrm{CO}_{2}$ rebreathing, see text) or two separate ports (C) 
pressure by passing through the expiratory valve and preventing $\mathrm{CO}_{2}$ rebreathing. In regard to the first aspect, it is worth noting that $\mathrm{H}$-CPAP requires lower fresh gas flows (in the range of $60 \mathrm{l} / \mathrm{min}$ ) than face masks (flows up to 100 or $120 \mathrm{l} / \mathrm{min}$ ) [6]. With a helmet, the airway pressure is also stable if the patient's peak inspiratory flow exceeds the fresh gas flow because of its high compliance (i.e. internal volume variations are accommodated with lowpressure variations). Conversely, the pressure in a "rigid" (i.e. with low compliance) system, such as a face mask, drops when the patient's peak demand is higher than the gas flow, resulting in additional work for the patient and possibly reduced alveolar end-expiratory pressure.

When using a helmet, assuring adequate washout of $\mathrm{CO}_{2}$ is of paramount importance. Patroniti et al. [7] showed that a fresh gas flow rate below $40 \mathrm{l} / \mathrm{min}$ leads to significant rebreathing of $\mathrm{CO}_{2}$ during inspiration. In line with these findings, Taccone et al. confirmed that significant $\mathrm{CO}_{2}$ rebreathing is present with a fresh gas flow rate of $30 \mathrm{l} / \mathrm{min}$ [8]. The same paper showed that the use of a mechanical ventilator, set in CPAP mode, should be absolutely avoided with a helmet: in this condition, the circulation of gas flowing through the system is similar to the patient's minute ventilation and hence totally inadequate to wash $\mathrm{CO}_{2}[8]$.

Different helmet brands and models vary in terms of sizing and the presence of auxiliary inputs and anchoring systems. Some helmets are equipped with anti-suffocation valves, which allow the patient to breathe room air in the case of fresh gas failure supply $[9,10]$. Some authors tested an interface combining high-flow nasal cannulas and H-CPAP in healthy volunteers [11].

On the expiratory limb, it is possible to employ either a water sealed or (more practically) mechanical valve. The ideal valve employs a threshold, rather than a constant, resistance, so that the pressure within the helmet remains constant irrespective of the flow [12].

The possibility of alternating two different PEEP valves on the expiratory limb has also been described as a way to provide nonsynchronized alternating pressure within the helmet, which can improve gas exchange in hypoxemic patients $[13,14]$.

High-flow nasal oxygen is gaining widespread use: it allows delivery of a known FiO2 and a mild level of PEEP. It is likely that this device might be as effective as $\mathrm{H}$-CPAP, particularly in less severe patients, although a direct comparison is missing.

\section{Clinical evidence for helmet CPAP}

The efficacy of NIV is well known during acute respiratory failure caused by cardiogenic pulmonary oedema
(CPE), where NIV reduces the intubation rate and mortality [15].

$\mathrm{H}$-CPAP appears to be an effective alternative to standard facemasks during CPE, even in cases of severe respiratory acidosis and hypercapnia [16]; in one of the earliest clinical studies on helmet use, Tonnelier et al. showed that $\mathrm{PaCO}_{2}$ progressively decreases towards normal values during the first 24 hours of H-CPAP treatment. In the same study, H-CPAP was applied in 11 patients and allowing CPAP to be applied for several hours without any reported adverse events or clinical intolerance [17].

$\mathrm{H}$-CPAP in CPE patients is feasible and can be safely applied in the prehospital setting. Foti et al. showed that early H-CPAP led to sudden and sustained improvement in respiratory function (peripheral oxygen saturation increased from $79 \pm 12$ to $97 \pm 3 \%$, and respiratory rate decreased from $26 \pm 4$ to $21 \pm 3$ breaths per minute) and circulatory function (systolic blood pressure decreased from $175 \pm 49$ to $145 \pm 28$, and heart rate decreased from $112 \pm 23$ to $105 \pm 19)$. H-CPAP even benefited patients rescued by nursing personnel only, hence in the absence of any pharmacological intervention [18, 19], implying that CPAP should be used as a first-line intervention even before standard medical treatment.

In the context of community-acquired pneumonia (CAP), a randomized controlled trial by Cosentini et al. in 2010 demonstrated how H-CPAP, in comparison with standard oxygen therapy using a Venturi mask, improved oxygenation faster $\left(\mathrm{PaO}_{2} / \mathrm{FiO}_{2}\right.$ ratio $\geq 315$ in $1.5 \mathrm{~h}$ vs. $48 \mathrm{~h}$ ) and in a greater number of patients ( $95 \%$ of patients vs. 30\%); however, improvements in oxygenation were lost after discontinuation of CPAP [20].

Moreover, in 2014, Brambilla et al. demonstrated that $\mathrm{H}$-CPAP, compared to standard oxygen, reduced the risk of endotracheal intubation, demonstrating the beneficial effects of this technique on a relevant clinical outcome [21].

H-CPAP can be a safe and effective treatment option for immunocompromised patients with ARF. Rabitsch et al. demonstrated that better tolerance to NIV achieved by using a helmet can lead to a higher rate of successful treatment (defined as an improved $\mathrm{PaO}_{2} / \mathrm{FiO}_{2}$ and decreased $\mathrm{PaCO}_{2}$ and respiratory rate) and might improve survival rates in immunocompromised patients [22]. Similarly, in a study from 2004 by Principi et al., CPAP tolerance was higher with helmet than face masks and was associated with a $49 \%$ reduction in the risk of death [23].

The feasibility and clinical effectiveness of H-CPAP in patients who developed ARF following surgery were demonstrated by several studies, in which H-CPAP was associated with improved gaseous exchange, preventing 
hypoxemia development and the need for endotracheal intubation [24-26].

Prophylactic postoperative H-CPAP in nonhypoxemic patients following pulmonary lobectomy transiently improved oxygenation and was associated with shorter hospital stays [27].

\section{COVID-19 experience}

Patients with coronavirus disease 2019 (COVID-19) pneumonia can develop severe hypoxemia and require PEEP, although these patients are at greater risk of NIV failure than patients with ARF with other aetiologies [28]. Some authors have suggested that helmets might reduce aerosol spread [29,30], as confirmed by some exploratory studies [31, 32].

Several authors have reported on the use of H-CPAP inside [33, 34] and outside the ICU in COVID-19 resource shortages [35-38]. Among others, Bellani et al. demonstrated, in a single-day observational study, that the H-CPAP success rate was greater than $60 \%$, and close to $75 \%$, in patients without a do-not-intubate (DNI) order. This study also highlighted known factors independently associated with NIV failure, such as age and $\mathrm{PaO}_{2} /$ $\mathrm{FiO}_{2}$ (threshold value of $150 \mathrm{mmHg}$ ), and others more specific to COVID-19, such as serum levels of C-reactive protein and platelet counts. [39].

In another study by Coppadoro et al., H-CPAP treatment after standard oxygen therapy failure was feasible for several days outside the ICU, despite persistent impairment in gas exchange. Helmet CPAP treatment was successful in $69 \%$ of patients without a DNI order, but DNI patients could also benefit from helmet CPAP as rescue therapy. Successful treatment with H-CPAP (hospital discharge without intubation) was associated with a nearly double response in oxygenation to the therapy $\left(\mathrm{PaO}_{2} / \mathrm{FiO}_{2}\right.$ ratio increase from 103 to $\left.202 \mathrm{mmHg}\right)$. In other words, as shown in Fig. 2, positive pressure not only improved oxygenation but also allowed better stratification of patient severity [40]. Some authors also suggested that an incremental PEEP trial might allow a PEEP selection with optimized oxygenation while avoiding haemodynamic complications [41].

Another observational, prospective study by Retucci et al. showed that patients with ARF might also benefit from prone positioning; H-CPAP allows safe early selfproning in awake, spontaneously breathing and nonintubated patients [42].

We found only one study on helmet NPPV in COVID: Grieco et al. compared helmet NPPV to highflow nasal oxygen (HFNO) showing that, $48 \mathrm{~h}$ after randomization, patients treated with helmet NPPV had better oxygenation, a lower respiratory rate and lower hypocapnia, albeit with greater device-related

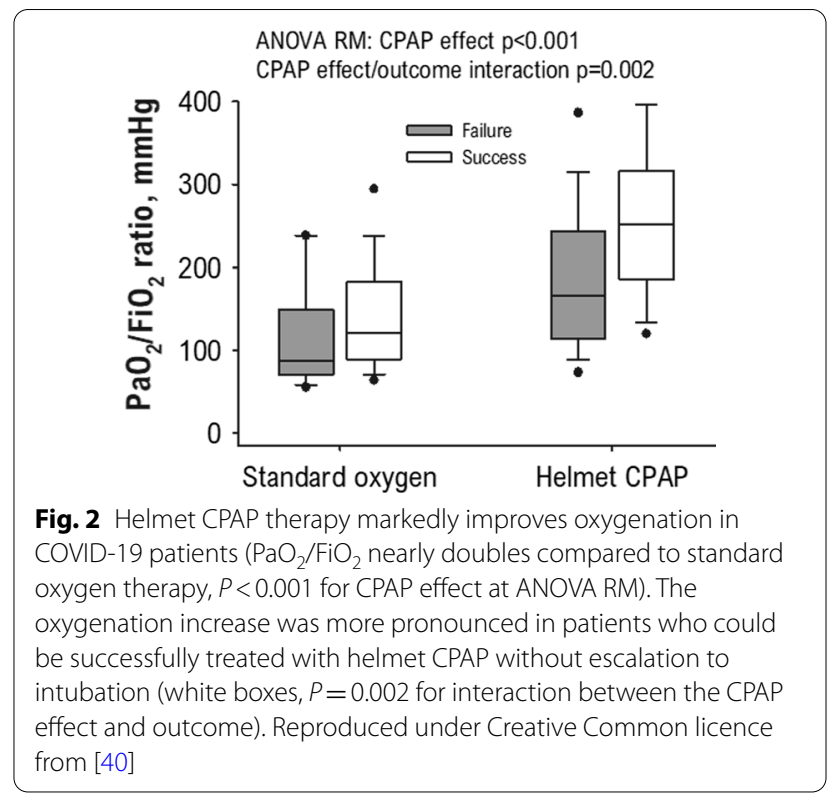

discomfort. The primary endpoint (days free of respiratory support) did not differ between the two arms, but the intubation rate was lower in patients treated with helmet therapy than in those treated with HFNO $(30 \%$ vs. $51 \%, P<0.03)[43]$.

\section{Use of helmets to deliver NPPV}

The most common method for providing assisted ventilation noninvasively (noninvasive positive pressure ventilation, NPPV) is with the use of a face mask connected to a ventilator. A positive pressure above the set PEEP level is delivered through an interface covering the patient's airway; helmets have been proposed to replace face masks due to the lower rate of complications during long-term therapy (e.g. pressure ulcers), with a comfort comparable to that of HFNO [44]. Moreover, end-expiratory lung volume is higher during helmet NPPV than during face mask NPPV, possibly due to reduced activation of expiratory muscles [45]. However, adequate pressurization of the large internal volume helmet and patient-ventilator interaction might be difficult to obtain: pressure support ventilation (PSV) is more efficiently delivered by a face mask than a helmet in terms of reduced work of breathing, lower time to reach the target pressure and higher airway pressure-time product during PSV [5]. Moreover, PSV delivered by a helmet is less effective in removing $\mathrm{CO}_{2}$ and is associated with a higher number of asynchronies than PSV delivered by a face mask [46]. The tidal volume measurement provided by the ventilator is not reliable when ventilating through a helmet, 
although recent reports suggest that such a measurement might be feasible with dedicated equipment [47].

\section{Use of specific ventilator settings}

In healthy subjects, increasing the level of pressure support during helmet NPPV results in increased tidal volume and reduced respiratory efforts [48]. However, the large helmet inner volume and compliance lead to delayed pressurization and reduced inspiratory pressure in the patient's airways, resulting in impaired patientventilator synchrony. Therefore, specific ventilator settings should be chosen when delivering NPPV thorough a helmet, such as a higher PEEP to stiffen the helmet, increased PSV level, higher pressurization time (i.e. low rise time) and cycling-off flow threshold [49-51].

To overcome the issues of slow pressurization and patient-ventilation interaction, novel helmets have been designed specifically for NPPV: a smaller internal volume and lower compliance resulted in better interaction in a bench study [52], while to improve comfort and synchrony, innovative helmet designs involve an internal inflatable collar $[53,54]$.

In healthy subjects undergoing NPPV, even an optimized helmet was not as efficient as a face mask with respect to ventilator triggering and cycling at low PEEP and PSV levels; at higher levels, it performed similarly to the face mask, with the advantage of reduced inspiratory effort [55]. The advantages of the novel helmet compared to the standard one were confirmed in a cohort of postextubation patients [56].

$\mathrm{CO}_{2}$ rebreathing is a key issue during helmet NPPV due to the greater amount of dead space than in a face mask; however, the effective dead space might be less than expected, as shown by mathematical modelling [57, 58]. The average helmet $\mathrm{CO}_{2}$ concentration depends primarily on $\mathrm{CO}_{2}$ production and total helmet ventilation (monitored by the ventilator as "minute ventilation"): higher pressure support levels, leading to increased minute ventilation, result in better $\mathrm{CO}_{2}$ washout (Fig. 3) [59].

The average helmet $\mathrm{CO}_{2}$ concentration can be quite high, reaching $18 \mathrm{mmHg}$ when using a standard doublelimb ventilator circuit connected to the helmet through a y-piece (Fig. 1); if the ventilator provides a flow-by and the circuit limbs are connected to two independent helmet ports without the y-piece, the helmet $\mathrm{CO}_{2}$ concentration is halved.

Compared to a standard double-limb circuit connected to the inspiratory and expiratory ports of the helmet, a single limb circuit with a modified expiratory valve placed on the helmet's expiratory port (open circuit) provides better $\mathrm{CO}_{2}$ washout $\left(\mathrm{PiCO}_{2}\right.$ reduced from 10 to $5 \mathrm{mmHg}$ ) but with slower pressurization [60].

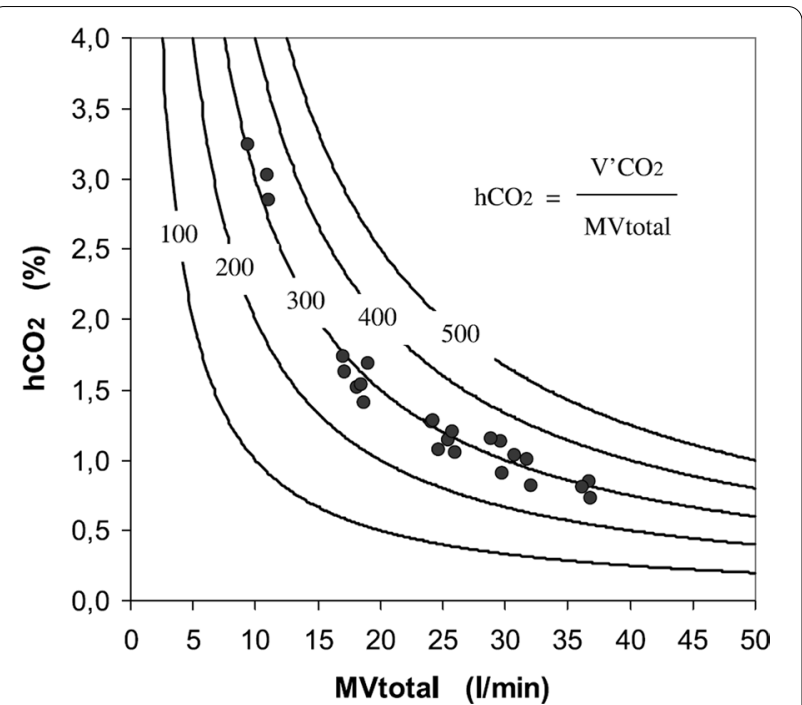

Fig. 3 The amount of "fresh" gas flowing through the helmet (MVtotal) determines the average $\mathrm{CO}_{2}$ concentration within the helmet $\left(\mathrm{hCO}_{2}\right)$. Circles represent measured data, while lines are the theoretical curves obtained by the equation reported in the graph at different levels of $\mathrm{CO}_{2}$ production. Reproduced from [59]

Compared with PSV, nonsynchronized high-flow biphasic positive airway pressure allows more efficient $\mathrm{CO}_{2}$ removal but with much worse patient-ventilator interaction [61].

\section{Patient-ventilator interaction}

Helmet NPPV is burdened by longer trigger delays and associated with increased tidal volumes, but asynchronies might be difficult to identify from ventilator traces $[62,63]$. The use of a double-limb circuit connected to the inspiratory and expiratory ports (no y-piece) improved synchrony in a bench study [64]. The cycling-off threshold (switch from inspiration to expiration) should be maintained at high levels (>30\%), particularly in COPD patients, as demonstrated in another bench study [65]. To obtain the best coupling between the neural inspiratory effort and pressure delivery by the ventilator, the use of assisted ventilation based on diaphragm electrical activity was investigated. In healthy subjects, patientventilator synchrony was improved, particularly at higher levels of support and respiratory rates [65, 66]. A better patient-ventilator interaction was also confirmed in two cohorts of postextubation patients $[67,68]$.

\section{Clinical indications and feasibility of helmet NPPV Acute hypoxemic respiratory failure}

In patients with hypoxemic respiratory failure treated by PSV, helmets were effective, and tolerance was higher 
than it was for face masks $[69,70]$. Among hypoxemic patients affected by community-acquired pneumonia, approximately $40 \%$ of the enrolled subjects were successfully treated with helmet NPPV; poor $\mathrm{PaO}_{2} / \mathrm{FiO}_{2}$ improvement after beginning helmet NPPV was associated with helmet failure and a subsequent need for intubation [71]. Despite sporadic use of the helmet in the USA, in 2016, Patel et al. conducted a pivotal randomized clinical trial on 200 patients comparing NPPV delivered by helmet vs. face mask in ARDS patients; the helmet proved superior, leading to a reduced need for intubation, lower ICU-acquired weakness and lower mortality rates [72]. The superiority of helmets is even more remarkable considering that the ventilator setting with the helmet was not optimized according to the principles described above and the likelihood that some $\mathrm{CO}_{2}$ rebreathing occurred. Moreover, helmet use could also be cost-effective [73, 74]. Helmet NPPV might also be used as an alternative to invasive ventilation during the weaning phase, with a similar ventilatory support duration but fewer infectious complications [75].

\section{COPD exacerbation}

Helmet NPPV was feasible for treatment of COPD exacerbation, although it was inferior to face mask NPPV for $\mathrm{CO}_{2}$ removal in an observational trial [26]. Two randomized trials confirmed that face mask ventilation is associated with significant $\mathrm{PaCO}_{2}$ reductions in COPD patients and that helmet NPPV is not comparably efficient $[76,77]$.

In a crossover clinical trial on a small population of patients with COPD, helmets and face masks were comparably tolerated and effective in improving hypercapnia; however, lower inspiratory efforts and better patient/ventilator interactions were recorded with face masks [78].

A later randomized clinical trial enrolling 80 patients with COPD exacerbation confirmed the same findings: helmets were equivalent to face masks in terms of discomfort, blood gas improvement and rate of intubation, while dyspnoea was reduced more effectively by face masks [79].

To overcome the synchronization and pressurization issues related to helmet NPPV, a system based on neurally adjusted ventilatory assist for helmet NPPV was tested in a small cohort of COPD patients, resulting in improved comfort and similar respiratory patterns and breathing efforts compared to face masks [80].

\section{Other populations}

Helmet NPPV was also feasible in hypoxemic immunocompromised patients, leading to better patient tolerance, fewer skin complications and lower discontinuation rates than face masks [81]. The use of helmet NPPV in postoperative respiratory failure patients was associated with a lower need for intubation and better tolerance [82].

\section{Key points for helmet NPPV}

Issues related to helmet NPPV are slow helmet pressurization, reduced $\mathrm{CO}_{2}$ washout and patient-ventilator asynchrony. Helmet NPPV is superior to face mask NPPV in ARDS patients and can be successfully used to treat hypoxemic patients; however, helmet NPPV is inferior in COPD patients. For optimal NPPV delivery, one should consider (1) helmets specifically designed for NPPV; (2) proper ventilator circuit connections to helmet inlet and outlet ports, avoiding the use of filters; (3) specific ventilator settings (high PEEP and assistance levels, low rise time and early cycling to expiration); and (4) neurally coupled ventilation to improve synchrony, particularly in COPD patients.

\section{Patient comfort, complications and other practical issues}

Patient comfort is essential during NIV to reduce potential complications leading to endotracheal intubation. Here, we summarize some practical interventions devised mainly for H-CPAP that are likely applicable to NPPV.

Some authors suggested that low-dose remifentanil could increase patients' tolerance to helmet and face mask NPPV [83]. Lucchini et al. proposed a "bundle of interventions" aimed at increasing the comfort of patients treated with helmet CPAP to increase the duration of treatment, including noise reduction [29].

The WHO guidelines recommend limiting ICU noise levels to between 45 and $60 \mathrm{~dB}$ during the daytime and $35 \mathrm{~dB}$ during the night-time. When a Venturi system is used to generate flow, the noise exposure is significantly more intense than ICU noise $[84,85]$, which may increase patient discomfort and affect ear function [86]; moreover, noise may decrease the acceptance of helmet use during long-term treatments.

Noise exposure during H-CPAP may be attenuated by positioning heat-moisture exchange filters on the inspiratory limb [87]. Other tools proposed to decrease patients' perceived noise include earplugs, sound traps and tubes with smooth inner surfaces $[84,85]$ and avoiding unnecessarily high flows.

Particularly, when dry medical gas is used for helmet CPAP, gas humidification can be far below the recommended value (10 mg H2O/l) [88]. 
The use of a heated humidifier allows adequate humidification while avoiding condensation but does not affect patients' level of comfort [88]; the humidifier should be adjusted at $26{ }^{\circ} \mathrm{C}$ with a temperature gradient that increases towards the patient $\left(+2{ }^{\circ} \mathrm{C}\right)$ [89]. Others have suggested that the best comfort is obtained by humidifying without heating [90].

The two most commonly used solutions for fixing $\mathrm{H}$-CPAP setups (a relevant aspect affecting patient tolerance) are armpit straps and counterweight systems. The armpit strap option may cause pain and pressure ulcers. The counterweight system seems to minimize these risks, yielding better tolerance (the force of gravity generated plus the placement of a pad cushion reduces the contact between skin and the device.) Delivering helmet CPAP with an armpit strap fixing system should be planned for short periods of time (no more than $2 \mathrm{~h}$ ). The counterweight option is indicated in the case of prolonged CPAP helmet cycles [91].

Unfortunately, while much attention has been devoted to patient (dis)comfort, only a few studies have systematically assessed and reported other types of complications. Specifically, adverse events (which are also the most relevant ones, in the opinion of the authors), including headache, otalgia, sensation of claustrophobia, cutaneous sores and ulcerations, have seldom been monitored. However, the incidence of these was found to be very low $[17,21,72]$.

\section{Use in the paediatric population}

In recent years, NIV has been increasingly applied to paediatric patients with different indications and settings [92]. NIV is also indicated in immunocompromised patients to avoid infectious complications following intubation $[92,93]$.

One of the key issues when delivering NIV among children is the interface. Among young children, H-CPAP can be used with a device modified in terms of size, with fastening achieved by a device called a "baby-body" [94]. With this kind of fastening system, the helmet is fastened around the baby's bottom instead of the classical armpits [95]. Even if H-CPAP can be as effective as nasal mask prongs to treat mild ARF or apnoea in preterm newborns [96], the latter are still the main interfaces used for newborns. This choice might also be explained by the higher noise of H-CPAP versus nasal prongs [97] and by the easier access to the baby to provide care with nasal mask/ prongs. Moreover, H-CPAP seems to reduce cerebral blood flow more than nasal masks [98]. Some authors have suggested that helmets allow effective delivery of nitric oxide [99] or aerosols [100].

Some authors tried to compare H-CPAP to nasal-facial masks among toddlers and children in terms of tolerance, efficacy and feasibility [101, 102]. Specifically, Chidini et al. [103, 104], in a randomized trial, found that $\mathrm{H}-\mathrm{CPAP}$ had a lower treatment failure rate due to intolerance $(3 / 17[17 \%]$ vs. $7 / 13$ [54\%], $P=0.009)$, and fewer infants required sedation $(6 / 17$ [35\%] vs. $13 / 13$ [100\%], $P=0.023)$. Moreover, they showed that H-CPAP is safe, even for prolonged use in acute clinical settings [105].

Since toddlers affected by bronchiolitis can also be treated with HFNO, one recent randomized controlled trial compared the efficacy of H-CPAP with HFNO: both systems were effective in improving the clinical conditions of patients with mild-to-moderate respiratory distress, and the response to helmet CPAP was more pronounced and rapid than that to HFNO, with a shorter hospitalization duration (4.9 vs. 13.1 Days $P=0.001$ ) and less use of steroids and salbutamol (3 vs. 7 Days $P=0.009$ ) in the first group [106]. The efficacy of $\mathrm{H}$-CPAP in bronchiolitis was also recently reported in a retrospective study [107]. Finally, post-transplant extubation respiratory failure has been effectively treated with H-CPAP [108].

Nasal or facial masks are the primary interfaces used for chronically ventilated patients (neuromuscular or genetic syndromes), with complication rates of up to $21 \%$ (discomfort, leaks, skin injuries), mandating systematic and close monitoring of the NPPV interface [109]. The lack of adoption of helmets in this setting can be explained by the difficulties associated with synchronization during pressure support: as reported by Conti et al. in one experimental model, helmets demonstrated the worst interaction (longest inspiratory trigger delay compared with the endotracheal tube and face mask), suggesting that face masks should be considered the first choice for delivering NPPV in children [110].

\section{Conclusions}

Relevant evidence has been published in the last 20 years, and several trials are ongoing [111-113]. The tragic COVID experience has led to more widespread use of helmets. Different technical solutions can be applied (free-flow CPAP vs. mechanical ventilator NPPV), and no data are available to establish whether either technique is superior. In any case, an adequate fresh gas flow must be provided to avoid $\mathrm{CO}_{2}$ rebreathing. As summarized above and by several meta-analyses [114-119], helmet 
therapy can be safely and effectively used to provide NIV during hypoxemic respiratory failure, better improving oxygenation than standard oxygen mask treatment and possibly leading to better patient-centred outcomes than other NIV interfaces.

\section{Abbreviations}

CPAP: Continuous positive airway pressure; H-CPAP: Helmet continuous positive airway pressure; NPPV: Noninvasive positive pressure ventilation; CPE: Cardiogenic pulmonary oedema; COVID-19: Coronavirus disease 2019; PEEP: Positive end-expiratory pressure; NIV: Noninvasive ventilatory support; COPD: Chronic obstructive pulmonary disease.

\section{Supplementary Information}

The online version contains supplementary material available at https://doi. org/10.1186/s13054-021-03746-8.

Additional file 1. List of papers retrived by literatire search but excluded from the review.

Additional file 2. Color image of helmet in a clinical scenario.

\section{Acknowledgements}

We gratefully acknowledge Dr. Ilaria Mariani (ASST-Monza, Monza, Italy) for material support in drafting the manuscript.

\section{Authors' contributions}

GB and $A C$ were involved in conception of the paper literature review, manuscript drafting and revision. EZ and FP were involved in literature search and manuscript drafting. GF was involved in substantial revision. All authors have approved the submitted version and are personally accountable for their own contributions. Allauthors read and approved the final manuscript.

\section{Funding}

None.

\section{Availability of supporting data}

Not applicable.

\section{Declarations}

\section{Ethical approval and consent to participate}

Not applicable.

\section{Consent for publication}

Figures reproduced with permission.

\section{Competing interests}

AC has a patent and received consultancy fees from Flowmeter for a topic possibly related to this article; GB has a patent and received consultancy fees from Flowmeter for a topic possibly related to this article and lecturing fees from Dimar SRL and Intersurgical SPA for topics related to this article; and GF received lecturing fees from Dimar SRL for topics related to this article. The other authors have no competing interests to disclose.

\section{Author details}

${ }^{1}$ ASST Monza, San Gerardo Hospital, Monza, Italy. ${ }^{2}$ Department of Medicine and Surgery, University of Milan-Bicocca, Via Cadore 48, Monza, MB, Italy.

Received: 7 June 2021 Accepted: 20 August 2021

Published online: 08 September 2021

\section{References}

1. Foti G, Cazzaniga M, Villa F, Valle E, Pesenti A. Out of hospital treatment of Acute pulmonary Edema (PE) by non invasive continuous positive airway pressure (CPAP). Intensive Care Med. 1999;112(Suppl):A431.

2. Villa F, Cereda M, Colombo E, Pesenti A. Evaluation of four noninvasive CPAP systems. Intensive Care Med. 1999;S66:A246.

3. Bellani G, Patroniti N, Greco M, Foti G, Pesenti A. The use of helmets to deliver non-invasive continuous positive airway pressure in hypoxemic acute respiratory failure. Minerva Anestesiol. 2008:74(11):651-6.

4. Crimi C, Noto A, Princi P, Nava S. Survey of non-invasive ventilation practices: a snapshot of Italian practice. Minerva Anestesiol. 2011;77(10):971-8.

5. Chiumello D, Pelosi P, Carlesso E, Severgnini P, Aspesi M, Gamberoni C, et al. Noninvasive positive pressure ventilation delivered by helmet vs. standard face mask. Intensive Care Med. 2003;29(10):1671-9.

6. Brusasco C, Corradi F, De Ferrari A, Ball L, Kacmarek RM, Pelosi P. CPAP devices for emergency prehospital use: a bench study. Respir Care. 2015;60(12):1777-85.

7. Patroniti N, Foti G, Manfio A, Coppo A, Bellani G, Pesenti A. Head helmet versus face mask for non-invasive continuous positive airway pressure: a physiological study. Intensive Care Med. 2003;29(10):1680-7.

8. Taccone P, Hess D, Caironi P, Bigatello LM. Continuous positive airway pressure delivered with a 'helmet': effects on carbon dioxide rebreathing. Crit Care Med. 2004;32(10):2090-6.

9. Milan M, Zanella A, Isgrò S, Deab SAEAES, Magni F, Pesenti A, et al. Performance of different continuous positive airway pressure helmets equipped with safety valves during failure of fresh gas supply. Intensive Care Med. 2011;37(6):1031-5.

10. Patroniti N, Saini M, Zanella A, Isgrò S, Pesenti A. Danger of helmet continuous positive airway pressure during failure of fresh gas source supply. Intensive Care Med. 2007:33(1):153-7.

11. Garofalo E, Bruni A, Pelaia C, Cammarota G, Murabito P, Biamonte E, et al. Evaluation of a new interface combining high-flow nasal cannula and CPAP. Respir Care. 2019;64(10):1231-9.

12. Isgrò S, Zanella A, Giani M, Abd El Aziz El Sayed Deab S, Pesenti A, Patroniti N. Performance of different PEEP valves and helmet outlets at increasing gas flow rates: a bench top study. Minerva Anestesiol. 2012;78(10):1095-100.

13. Cammarota G, Vaschetto R, Turucz E, Dellapiazza F, Colombo D, Blando $C$, et al. Influence of lung collapse distribution on the physiologic response to recruitment maneuvers during noninvasive continuous positive airway pressure. Intensive Care Med. 2011;37(7):1095-102.

14. Isgrò S, Zanella A, Sala C, Grasselli G, Foti G, Pesenti A, et al. Continuous flow biphasic positive airway pressure by helmet in patients with acute hypoxic respiratory failure: effect on oxygenation. Intensive Care Med. 2010;36(10):1688-94.

15. Berbenetz N, Wang Y, Brown J, Godfrey C, Ahmad M, Vital FM, et al. Non-invasive positive pressure ventilation (CPAP or bilevel NPPV) for cardiogenic pulmonary oedema. Cochrane Database Syst Rev. 2019;4:CD005351

16. Sforza A, Guarino M, Cimmino CS, Izzo A, Cristiano G, Mancusi C, et al. Continuous positive airway pressure therapy in the management of hypercapnic cardiogenic pulmonary edema. Monaldi Arch Chest Dis. 2021.

17. Tonnelier J-M, Prat G, Nowak E, Goetghebeur D, Renault A, Boles JM, et al. Noninvasive continuous positive airway pressure ventilation using a new helmet interface: a case-control prospective pilot study. Intensive Care Med. 2003;29(11):2077-80.

18. Foti G, Sangalli F, Berra L, Sironi S, Cazzaniga M, Rossi GP, et al. Is helmet CPAP first line pre-hospital treatment of presumed severe acute pulmonary edema? Intensive Care Med. 2009;35(4):656-62.

19. Garuti G, Bandiera G, Cattaruzza MS, Gelati L, Osborn JF, Toscani S, et al. Out-of-hospital helmet CPAP in acute respiratory failure reduces mortality: a study led by nurses. Monaldi Arch Chest Dis. 2010;73(4):145-51.

20. Cosentini R, Brambilla AM, Aliberti S, Bignamini A, Nava S, Maffei A, et al. Helmet continuous positive airway pressure vs oxygen therapy to improve oxygenation in community-acquired pneumonia: a randomized, controlled trial. Chest. 2010;138(1):114-20.

21. Brambilla AM, Aliberti S, Prina E, Nicoli F, Del Forno M, Nava S, et al. Helmet CPAP vs. oxygen therapy in severe hypoxemic respiratory failure due to pneumonia. Intensive Care Med. 2014;40(7):942-9. 
22. Rabitsch W, Schellongowski P, Köstler WJ, Stoiser B, Knöbl P, Locker GJ, et al. Efficacy and tolerability of non-invasive ventilation delivered via a newly developed helmet in immunosuppressed patients with acute respiratory failure. Wien Klin Wochenschr. 2003;115(15-16):590-4.

23. Principi T, Pantanetti S, Catani F, Elisei D, Gabbanelli V, Pelaia P, et al. Noninvasive continuous positive airway pressure delivered by helmet in hematological malignancy patients with hypoxemic acute respiratory failure. Intensive Care Med. 2004;30(1):147-50.

24. Redondo Calvo FJ, Madrazo M, Gilsanz F, Uña R, Villazala R, Bernal G. Helmet noninvasive mechanical ventilation in patients with acute postoperative respiratory failure. Respir Care. 2012;57(5):743-52.

25. Redondo Calvo FJ, Bejarano Ramirez N, Uña Orejon R, Villazala Garcia R, Yuste Peña AS, Belda FJ. Elevated Extravascular Lung Water Index (ELWI) as a predictor of failure of continuous positive airway pressure via helmet (Helmet-CPAP) in patients with acute respiratory failure after major surgery. Arch Bronconeumol. 2015;51(11):558-63.

26. Antonelli M, Pennisi MA, Pelosi P, Gregoretti C, Squadrone V, Rocco $M$, et al. Noninvasive positive pressure ventilation using a helmet in patients with acute exacerbation of chronic obstructive pulmonary disease: a feasibility study. Anesthesiology. 2004;100(1):16-24.

27. Barbagallo M, Ortu A, Spadini E, Salvadori A, Ampollini L, Internullo $\mathrm{E}$, et al. Prophylactic use of helmet CPAP after pulmonary lobectomy: a prospective randomized controlled study. Respir Care. 2012;57(9):1418-24.

28. Menga LS, Cese LD, Bongiovanni F, Lombardi G, Michi T, Luciani F, et al. High failure rate of noninvasive oxygenation strategies in critically III subjects with acute hypoxemic respiratory failure due to COVID-19. Respir Care. 2021;66(5):705-14.

29. Lucchini A, Giani M, Isgrò S, Rona R, Foti G. The 'helmet bundle' in COVID-19 patients undergoing non invasive ventilation. Intensive Crit Care Nurs. 2020;58:102859.

30. Patout M, Fresnel E, Lujan M, Rabec C, Carlucci A, Razakamanantsoa $\mathrm{L}$, et al. Recommended approaches to minimize aerosol dispersion of SARS-CoV-2 during noninvasive ventilatory support can cause ventilator performance deterioration: a benchmark comparative study. Chest. 2021.

31. Ferioli M, Cisternino C, Leo V, Pisani L, Palange P, Nava S. Protecting healthcare workers from SARS-CoV-2 infection: practical indications. Eur Respir Rev. 2020;29(155):200068.

32. Hui DS, Chow BK, Lo T, Ng SS, Ko FW, Gin T, et al. Exhaled air dispersion during noninvasive ventilation via helmets and a total facemask. Chest. 2015;147(5):1336-43.

33. Alharthy A, Faqihi F, Noor A, Soliman I, Brindley PG, Karakitsos D, et al. Helmet continuous positive airway pressure in the treatment of COVID-19 Patients With Acute Respiratory Failure Could Be An Effective Strategy: A Feasibility Study. J Epidemiol Glob Health. 2020;10(3):201-3.

34. Gaulton TG, Bellani G, Foti G, Frazer MJ, Fuchs BD, Cereda M. Early clinical experience in using helmet continuous positive airway pressure and high-flow nasal cannula in overweight and obese patients with acute hypoxemic respiratory failure from coronavirus disease 2019. Crit Care Explor. 2020;2(9):e0216.

35. Aliberti S, Radovanovic D, Billi F, Sotgiu G, Costanzo M, Pilocane T, et al. Helmet CPAP treatment in patients with COVID-19 pneumonia: a multicentre cohort study. Eur Respir J. 2020;56(4):2001935.

36. Bastoni D, Poggiali E, Vercelli A, Demichele E, Tinelli V, lannicelli T, et al. Prone positioning in patients treated with non-invasive ventilation for COVID-19 pneumonia in an Italian emergency department. Emerg Med J. 2020;37(9):565-6.

37. Duca A, Memaj I, Zanardi F, Preti C, Alesi A, DellaBella L, et al. Severity of respiratory failure and outcome of patients needing a ventilatory support in the Emergency Department during Italian novel coronavirus SARS-CoV2 outbreak: preliminary data on the role of helmet CPAP and non-invasive positive pressure ventilation. EClinicalMedicine. 2020:24:100419.

38. Indini A, Aschele C, Cavanna L, Clerico M, Daniele B, Fiorentini G, et al. Reorganisation of medical oncology departments during the novel coronavirus disease-19 pandemic: a nationwide Italian survey. Eur J Cancer. 2020;132:17-23.

39. Bellani G, Grasselli G, Cecconi M, Antolini L, Borelli M, De Giacomi F, et al. Noninvasive ventilatory support of COVID-19 patients outside the intensive care units (WARd-COVID). Ann Am Thorac Soc. 2021.
40. Coppadoro A, Benini A, Fruscio R, Verga L, Mazzola P, Bellelli G, et al. Helmet CPAP to treat hypoxic pneumonia outside the ICU: an observational study during the COVID-19 outbreak. Crit Care. 2021;25(1):80.

41. Amati F, Aliberti S, Misuraca S, Simonetta E, Bindo F, Vigni A, et al. Lung recruitability of COVID-19 pneumonia in patients undergoing helmet CPAP. Arch Bronconeumol. 2021;57(Suppl 1):92-4.

42. Retucci M, Aliberti S, Ceruti C, Santambrogio M, Tammaro S, Cuccarini F, et al. Prone and lateral positioning in spontaneously breathing patients with COVID-19 pneumonia undergoing noninvasive helmet CPAP treatment. Chest. 2020;158(6):2431-5.

43. Grieco DL, Menga LS, Cesarano M, Rosà T, Spadaro S, Bitondo MM, et al. Effect of helmet noninvasive ventilation vs high-flow nasal oxygen on days free of respiratory support in patients with COVID-19 and moderate to severe hypoxemic respiratory failure: the HENIVOT randomized clinical trial. JAMA. 2021;325(17):1731-43.

44. Grieco DL, Menga LS, Raggi V, Bongiovanni F, Anzellotti GM, Tanzarella ES, et al. Physiological comparison of high-flow nasal cannula and helmet noninvasive ventilation in acute hypoxemic respiratory failure. Am J Respir Crit Care Med. 2020;201(3):303-12.

45. Tatham KC, Ko M, Palozzi L, Lapinsky SE, Brochard LJ, Goligher EC. Helmet interface increases lung volumes at equivalent ventilator pressures compared to the face mask interface during non-invasive ventilation. Crit Care. 2020;24(1):504.

46. Racca F, Appendini L, Gregoretti C, Stra E, Patessio A, Donner CF, et al. Effectiveness of mask and helmet interfaces to deliver noninvasive ventilation in a human model of resistive breathing. J Appl Physiol. 2005;99(4):1262-71.

47. Cortegiani A, Navalesi P, Accurso G, Sabella I, Misseri G, Ippolito M, et al. Tidal volume estimation during helmet noninvasive ventilation: an experimental feasibility study. Sci Rep. 2019;9(1):17324.

48. Costa R, Navalesi P, Antonelli M, Cavaliere F, Craba A, Proietti R, et al. Physiologic evaluation of different levels of assistance during noninvasive ventilation delivered through a helmet. Chest. 2005;128(4):2984-90.

49. Moerer O, Fischer S, Hartelt M, Kuvaki B, Quintel M, Neumann P. Influence of two different interfaces for noninvasive ventilation compared to invasive ventilation on the mechanical properties and performance of a respiratory system: a lung model study. Chest. 2006;129(6):1424-31.

50. Vargas F, Thille A, Lyazidi A, Campo FR, Brochard L. Helmet with specific settings versus facemask for noninvasive ventilation. Crit Care Med. 2009;37(6):1921-8.

51. Costa R, Navalesi P, Spinazzola G, Ferrone G, Pellegrini A, Cavaliere F, et al. Influence of ventilator settings on patient-ventilator synchrony during pressure support ventilation with different interfaces. Intensive Care Med. 2010;36(8):1363-70.

52. Costa R, Navalesi P, Spinazzola G, Rossi M, Cavaliere F, Antonelli M, et al. Comparative evaluation of different helmets on patient-ventilator interaction during noninvasive ventilation. Intensive Care Med. 2008;34(6):1102-8.

53. Mojoli F, lotti GA, Currò I, Pozzi M, Via G, Venti A, et al. An optimized set-up for helmet noninvasive ventilation improves pressure support delivery and patient-ventilator interaction. Intensive Care Med. 2013;39(1):38-44.

54. Olivieri C, Costa R, Spinazzola G, Ferrone G, Longhini F, Cammarota G, et al. Bench comparative evaluation of a new generation and standard helmet for delivering non-invasive ventilation. Intensive Care Med. 2013;39(4):734-8.

55. Vaschetto R, De Jong A, Conseil M, Galia F, Mahul M, Coisel Y, et al. Comparative evaluation of three interfaces for non-invasive ventilation: a randomized cross-over design physiologic study on healthy volunteers. Crit Care. 2014;18(1):R2.

56. Olivieri C, Longhini F, Cena T, Cammarota G, Vaschetto R, Messina A, et al. New versus conventional helmet for delivering noninvasive ventilation: a physiologic, crossover randomized study in critically III patients. Anesthesiology. 2016;124(1):101-8.

57. Gil A, Martínez M, Quintero P, Medina A. Computational evaluation of rebreathing and effective dead space on a helmet-like interface during the COVID-19 pandemic. J Biomech. 2021;118:110302.

58. Fodil R, Lellouche F, Mancebo J, Sbirlea-Apiou G, Isabey D, Brochard L, et al. Comparison of patient-ventilator interfaces based on their computerized effective dead space. Intensive Care Med. 2011;37(2):257-62. 
59. Mojoli F, lotti GA, Gerletti M, Lucarini C, Braschi A. Carbon dioxide rebreathing during non-invasive ventilation delivered by helmet: a bench study. Intensive Care Med. 2008:34(8):1454-60.

60. Racca F, Appendini L, Gregoretti C, Varese I, Berta G, Vittone F, et al. Helmet ventilation and carbon dioxide rebreathing: effects of adding a leak at the helmet ports. Intensive Care Med. 2008;34(8):1461-8.

61. Moerer $\mathrm{O}$, Herrmann $\mathrm{P}$, Hinz J, Severgnini P, Calderini E, Quintel M, et al. High flow biphasic positive airway pressure by helmet-effects on pressurization, tidal volume, carbon dioxide accumulation and noise exposure. Crit Care. 2009;13(3):R85.

62. Oda S, Otaki K, Yashima N, Kurota M, Matsushita S, Kumasaka A, et al. Work of breathing using different interfaces in spontaneous positive pressure ventilation: helmet, face-mask, and endotracheal tube. J Anesth. 2016;30(4):653-62.

63. Longhini F, Colombo D, Pisani L, Idone F, Chun P, Doorduin J, et al. Efficacy of ventilator waveform observation for detection of patientventilator asynchrony during NIV: a multicentre study. ERJ Open Res. 2017;3(4)

64. Ferrone G, Cipriani F, Spinazzola G, Festa O, Arcangeli A, Proietti R, et al. A bench study of 2 ventilator circuits during helmet noninvasive ventilation. Respir Care. 2013;58(9):1474-81.

65. Moerer O, Harnisch L-O, Herrmann P, Zippel C, Quintel M. Patient-ventilator interaction during noninvasive ventilation in simulated COPD. Respir Care. 2016;61(1):15-22.

66. Moerer O, Beck J, Brander L, Costa R, Quintel M, Slutsky AS, et al. Subject-ventilator synchrony during neural versus pneumatically triggered non-invasive helmet ventilation. Intensive Care Med. 2008;34(9):1615-23

67. Cammarota G, Olivieri C, Costa R, Vaschetto R, Colombo D, Turucz $E$, et al. Noninvasive ventilation through a helmet in postextubation hypoxemic patients: physiologic comparison between neurally adjusted ventilatory assist and pressure support ventilation. Intensive Care Med. 2011;37(12):1943-50.

68. Cammarota G, Longhini F, Perucca R, Ronco C, Colombo D, Messina A, et al. New setting of neurally adjusted ventilatory assist during noninvasive ventilation through a helmet. Anesthesiology. 2016;125(6):1181-9.

69. Antonelli M, Conti G, Pelosi P, Gregoretti C, Pennisi MA, Costa R, et al. New treatment of acute hypoxemic respiratory failure: noninvasive pressure support ventilation delivered by helmet-a pilot controlled trial. Crit Care Med. 2002;30(3):602-8.

70. Liu Q, Shan M, Zhu H, Cao J, Chen R. Noninvasive ventilation with a helmet in patients with acute respiratory failure caused by chest trauma: a randomized controlled trial. Sci Rep. 2020;10(1):21489.

71. Carron M, Freo U, Zorzi M, Ori C. Predictors of failure of noninvasive ventilation in patients with severe community-acquired pneumonia. J Crit Care. 2010;25(3):540.e9-14

72. Patel BK, Wolfe KS, PohIman AS, Hall JB, Kress JP. Effect of noninvasive ventilation delivered by helmet vs face mask on the rate of endotracheal intubation in patients with acute respiratory distress syndrome: a randomized clinical trial. JAMA. 2016;315(22):2435-41.

73. Kyeremanteng K, Gagnon L-P, Robidoux R, Thavorn K, Chaudhuri D, Kobewka D, et al. Cost analysis of noninvasive helmet ventilation compared with use of noninvasive face mask in ARDS. Can Respir J. 2018;2018:6518572.

74. Patel BK, Wolfe KS, MacKenzie EL, Salem D, Esbrook CL, Pawlik AJ, et al. One-year outcomes in patients with acute respiratory distress syndrome enrolled in a randomized clinical trial of helmet versus facemask noninvasive ventilation. Crit Care Med. 2018;46(7):1078-84.

75. Carron M, Rossi S, Carollo C, Ori C. Comparison of invasive and noninvasive positive pressure ventilation delivered by means of a helmet for weaning of patients from mechanical ventilation. J Crit Care. 2014;29(4):580-5.

76. Antonaglia V, Ferluga M, Molino R, Lucangelo U, Peratoner A, RomanPognuz $\mathrm{E}$, et al. Comparison of noninvasive ventilation by sequential use of mask and helmet versus mask in acute exacerbation of chronic obstructive pulmonary disease: a preliminary study. Respiration. 2011;82(2):148-54.

77. Özlem ÇG, Ali A, Fatma U, Mehtap T, Şaziye Ş. Comparison of helmet and facial mask during noninvasive ventilation in patients with acute exacerbation of chronic obstructive pulmonary disease: a randomized controlled study. Turk J Med Sci. 2015;45(3):600-6.
78. Navalesi P, Costa R, Ceriana P, Carlucci A, Prinianakis G, Antonelli M, et al. Non-invasive ventilation in chronic obstructive pulmonary disease patients: helmet versus facial mask. Intensive Care Med. 2007;33(1):74-81

79. Pisani L, Mega C, Vaschetto R, Bellone A, Scala R, Cosentini R, et al. Oronasal mask versus helmet in acute hypercapnic respiratory failure. Eur Respir J. 2015;45(3):691-9.

80. Longhini F, Liu L, Pan C, Xie J, Cammarota G, Bruni A, et al. Neurallyadjusted ventilatory assist for noninvasive ventilation via a helmet in subjects with COPD exacerbation: a physiologic study. Respir Care. 2019;64(5):582-9.

81. Rocco M, Dell'Utri D, Morelli A, Spadetta G, Conti G, Antonelli M, et al. Noninvasive ventilation by helmet or face mask in immunocompromised patients: a case-control study. Chest. 2004;126(5):1508-15.

82. Conti G, Cavaliere F, Costa R, Craba A, Catarci S, Festa V, et al. Noninvasive positive-pressure ventilation with different interfaces in patients with respiratory failure after abdominal surgery: a matched-control study. Respir Care. 2007;52(11):1463-71.

83. Rocco M, Conti G, Alessandri E, Morelli A, Spadetta G, Laderchi A, et al. Rescue treatment for noninvasive ventilation failure due to interface intolerance with remifentanil analgosedation: a pilot study. Intensive Care Med. 2010;36(12):2060-5.

84. Lucchini A, Bambi S, Gurini S, Di Francesco E, Pace L, Rona R, et al. Noise Level and Comfort in Healthy Subjects Undergoing High-Flow Helmet Continuous Positive Airway Pressure. Dimens Crit Care Nurs. 2020;39(4):194-202.

85. Cavaliere F, Conti G, Costa R, Proietti R, Sciuto A, Masieri S. Noise exposure during noninvasive ventilation with a helmet, a nasal mask, and a facial mask. Intensive Care Med. 2004;30(9):1755-60.

86. Cavaliere F, Masieri S, Conti G, Antonelli M, Pennisi MA, Filipo R, et al. Effects of non-invasive ventilation on middle ear function in healthy volunteers. Intensive Care Med. 2003;29(4):611-4.

87. Hernández-Molina R, Fernández-Zacarías F, Benavente-Fernández I, Jiménez-Gómez G, Lubián-López S. Effect of filters on the noise generated by continuous positive airway pressure delivered via a helmet. Noise Health. 2017;19(86):20-3.

88. Chiumello D, Chierichetti M, Tallarini F, Cozzi P, Cressoni M, Polli F, et al. Effect of a heated humidifier during continuous positive airway pressure delivered by a helmet. Crit Care. 2008;12(2):R55.

89. Lucchini A, Bambi S, Elli S, Bruno M, Dallari R, Puccio P, et al. Water content of delivered gases during helmet continuous positive airway pressure in healthy subjects. Acta Biomed. 2019:90(11-S):65-71.

90. Ueta K, Tomita T, Uchiyama A, Ohta N, Iguchi N, Goto Y, et al. Influence of humidification on comfort during noninvasive ventilation with a helmet. Respir Care. 2013;58(5):798-804.

91. Lucchini A, Elli S, Bambi S, De Felippis C, Vimercati S, Minotti D, et al. How different helmet fixing options could affect patients' pain experience during helmet-continuous positive airway pressure. Nurs Crit Care. 2019;24(6):369-74.

92. Calderini E, Chidini G, Pelosi P. What are the current indications for noninvasive ventilation in children? Curr Opin Anaesthesiol. 2010;23(3):368-74.

93. Piastra M, Antonelli M, Chiaretti A, Polidori G, Polidori L, Conti G. Treatment of acute respiratory failure by helmet-delivered non-invasive pressure support ventilation in children with acute leukemia: a pilot study. Intensive Care Med. 2004;30(3):472-6.

94. Piastra M, De Luca D, Pietrini D, Pulitanò S, D'Arrigo S, Mancino A, et al. Noninvasive pressure-support ventilation in immunocompromised children with ARDS: a feasibility study. Intensive Care Med. 2009;35(8):1420-7.

95. Codazzi D, Nacoti M, Passoni M, Bonanomi E, Sperti LR, Fumagalli R. Continuous positive airway pressure with modified helmet for treatment of hypoxemic acute respiratory failure in infants and a preschool population: a feasibility study. Pediatr Crit Care Med. 2006;7(5):455-60.

96. Trevisanuto D, Grazzina N, Doglioni N, Ferrarese P, Marzari F, Zanardo V. A new device for administration of continuous positive airway pressure in preterm infants: comparison with a standard nasal CPAP continuous positive airway pressure system. Intensive Care Med. 2005;31 (6):859-64.

97. Trevisanuto D, Camiletti L, Doglioni N, Cavallin F, Udilano A, Zanardo $\checkmark$. Noise exposure is increased with neonatal helmet CPAP in 
comparison with conventional nasal CPAP. Acta Anaesthesiol Scand. 2011;55(1):35-8.

98. Zaramella P, Freato F, Grazzina N, Saraceni E, Vianello A, Chiandetti L. Does helmet CPAP reduce cerebral blood flow and volume by comparison with Infant Flow driver CPAP in preterm neonates? Intensive Care Med. 2006;32(10):1613-9.

99. Trevisanuto D, Doglioni N, Micaglio M, Zanardo V. Feasibility of nitric oxide administration by neonatal helmet-CPAP: a bench study. Paediatr Anaesth. 2007:17(9):851-5.

100. Rodriguez Garcia L, Medina A, Modesto I, Alapont V, Palacios Loro ML, Mayordomo-Colunga J, Vivanco-Allende A, et al. Safety of aerosol therapy in children during noninvasive ventilation with helmet and total face mask. Med Intensiva. 2019;43(8):474-9.

101. Milési C, Ferragu F, Jaber S, Rideau A, Combes C, Matecki S, et al. Continuous positive airway pressure ventilation with helmet in infants under 1 year. Intensive Care Med. 2010;36(9):1592-6.

102. Mayordomo-Colunga J, Rey C, Medina A, Martínez-Camblor P, VivancoAllende A, Concha A. Helmet versus nasal-prong CPAP in infants with acute bronchiolitis. Respir Care. 2018;63(4):455-63.

103. Chidini G, Calderini E, Pelosi P. Treatment of acute hypoxemic respiratory failure with continuous positive airway pressure delivered by a new pediatric helmet in comparison with a standard full face mask: a prospective pilot study. Pediatr Crit Care Med. 2010;11(4):502-8.

104. Chidini G, Calderini E, Cesana BM, Gandini C, Prandi E, Pelosi P. Noninvasive continuous positive airway pressure in acute respiratory failure: helmet versus facial mask. Pediatrics. 2010;126(2):e330-336.

105. Chidini G, Piastra M, Marchesi T, De Luca D, Napolitano L, Salvo I, et al. Continuous positive airway pressure with helmet versus mask in infants with bronchiolitis: an RCT. Pediatrics. 2015;135(4):e868-875.

106. Vitaliti G, Vitaliti MC, Finocchiaro MC, Di Stefano VA, Pavone P, Matin $\mathrm{N}$, et al. Randomized comparison of helmet CPAP versus high-flow nasal cannula oxygen in pediatric respiratory distress. Respir Care. 2017:62(8):1036-42.

107. Rossetti E, De Galasso L, Appierto L, Bianchi R, Chiusolo F, Germani A, et al. Retrospective study found that helmet continuous positive airway pressure provided effective support for severe bronchiolitis. Acta Paediatr. 2020;109(12):2671-3.

108. Chiusolo F, Fanelli V, Ciofi Degli Atti ML, Conti G, Tortora F, Pariante R, et al. CPAP by helmet for treatment of acute respiratory failure after pediatric liver transplantation. Pediatr Transplant. 2018;22(1):e13088

109. Ramirez A, Delord V, Khirani S, Leroux K, Cassier S, Kadlub N, et al. Interfaces for long-term noninvasive positive pressure ventilation in children. Intensive Care Med. 2012;38(4):655-62.
110. Conti G, Gregoretti C, Spinazzola G, Festa O, Ferrone G, Cipriani F, et al. Influence of different interfaces on synchrony during pressure support ventilation in a pediatric setting: a bench study. Respir Care. 2015;60(4):498-507.

111. Cortegiani A, Longhini F, Carlucci A, Scala R, Groff P, Bruni A, et al. Highflow nasal therapy versus noninvasive ventilation in COPD patients with mild-to-moderate hypercapnic acute respiratory failure: study protocol for a noninferiority randomized clinical trial. Trials. 2019;20(1):450.

112. Khatib MY, Peediyakkal MZ, Elshafei MS, Elzeer HS, Ananthegowda DC Shahen MA, et al. Comparison of the clinical outcomes of non-invasive ventilation by helmet vs facemask in patients with acute respiratory distress syndrome. Medicine. 2021;100(4):e24443.

113. Tverring J, Åkesson A, Nielsen N. Helmet continuous positive airway pressure versus high-flow nasal cannula in COVID-19: a pragmatic randomised clinical trial (COVID HELMET). Trials. 2020;21(1):994.

114. Luo Y, Luo Y, Li Y, Zhou L, Zhu Z, Chen Y, et al. Helmet CPAP versus oxygen therapy in hypoxemic acute respiratory failure: a meta-analysis of randomized controlled trials. Yonsei Med J. 2016:57(4):936-41.

115. Xu X-P, Zhang X-C, Hu S-L, Xu J-Y, Xie J-F, Liu S-Q, et al. Noninvasive ventilation in acute hypoxemic nonhypercapnic respiratory failure: a systematic review and meta-analysis. Crit Care Med. 2017;45(7):e727-33.

116. Wang $T$, Yin $H, X u$ Q, Jiang X, Yu T. Use of a helmet for oxygen therapy in critically ill patients: a systematic review and meta-analysis. J Int Med Res. 2020;48(2):300060520903209.

117. Ferreyro BL, Angriman F, Munshi L, Del Sorbo L, Ferguson ND, Rochwerg $B$, et al. Noninvasive oxygenation strategies in adult patients with acute respiratory failure: a protocol for a systematic review and network meta-analysis. Syst Rev. 2020;9(1):95

118. Ferreyro BL, Angriman F, Munshi L, Sorbo LD, Ferguson ND, Rochwerg B, et al. Association of noninvasive oxygenation strategies with all-cause mortality in adults with acute hypoxemic respiratory failure: a systematic review and meta-analysis. JAMA [Internet]. 2020 Jun 4 [cited 2020 Jun 10]; Available from: https://jamanetwork.com/journals/jama/fulla rticle/2767025

119. Liu Q, Gao Y, Chen R, Cheng Z. Noninvasive ventilation with helmet versus control strategy in patients with acute respiratory failure: a systematic review and meta-analysis of controlled studies. Crit Care. 2016;23(20):265.

\section{Publisher's Note}

Springer Nature remains neutral with regard to jurisdictional claims in published maps and institutional affiliations.
Ready to submit your research? Choose BMC and benefit from:

- fast, convenient online submission

- thorough peer review by experienced researchers in your field

- rapid publication on acceptance

- support for research data, including large and complex data types

- gold Open Access which fosters wider collaboration and increased citations

- maximum visibility for your research: over $100 \mathrm{M}$ website views per year

At BMC, research is always in progress.

Learn more biomedcentral.com/submissions 